\title{
Modelling temporal changes of nitrogen dioxide concentrations in an urban area
}

\author{
C. Capilla \\ Department of Applied Statistics and Operations Research and Quality, \\ Universidad Politécnica de Valencia, Spain
}

\begin{abstract}
Meteorological variability must be taken into account in the modelling of temporal changes in air pollutants to evaluate emissions reduction strategies. In this paper nitrogen dioxide $\left(\mathrm{NO}_{2}\right)$ hourly data are analyzed at two monitoring stations in Valencia (Spain). Meteorologically-adjusted nitric oxide (NO) is used as an indicator of traffic density. The low-pass filter developed by Kolmogorov and Zurbenko is used to split the logarithm of $\mathrm{NO}_{2}$ and $\mathrm{NO}$ hourly concentrations into long-term, seasonal and short-term components. Meteorological effects are analyzed and removed from filtered pollutants time series. Forward stepwise regression is employed to select the filtered meteorological variables that explain more variability. A natural logarithmic transformation is applied to the series of hourly data and the model for the hourly pollutants concentrations is multiplicative. The dependencies of urban $\mathrm{NO}_{2}$ on the corresponding vehicular emissions and relevant meteorological parameters are non-linear. Long-term components represent a small amount in the overall variability of air pollution data. Seasonal and short-term components mask the underlying relationship between $\mathrm{NO}_{2}$ and emissions if studied as a whole. The pollutant temporal components have to be studied separately due to their different physical and explanatory mechanisms.

Keywords: air pollution, Kolmogorov-Zurbenko filter, nitrogen dioxide, temporal changes, urban air quality.
\end{abstract}

\section{Introduction}

Air pollution in urban areas is regarded as a growing problem for communities. Some compounds like ozone, nitrogen oxides, sulphur dioxide and atmospheric 
particulates are considered indicators of air quality in urban areas. Several studies have reported connections between chronic morbidity or mortality and urban pollution $[1,2]$. These connections have led administrations to introduce plans and regulations to reduce pollutants emissions. Modelling variations in pollutants concentrations is useful when evaluating the effectiveness of these plans. If long-term trends and short-term components of pollutants emissions are to be analyzed, meteorological effects have to be removed from the times series due to their strong masking effects. The Kolmogorov-Zurbenko (KZ) filter has been developed with the aim of moderating the effects of meteorology in pollutants time series [3].

This paper is an application of the $\mathrm{KZ}$ filter to analyze temporal changes in nitrogen dioxide $\left(\mathrm{NO}_{2}\right)$ for two locations inside the Valencia urban area (Spain). Air pollution in Valencia mainly derives from motor vehicle emissions. Previous studies in this city have shown a significant connection between a $10 \mu \mathrm{g} / \mathrm{m}^{3}$ increase in $\mathrm{NO}_{2}$ level and asthma, measured as a relative risk of emergency visits [4]. Other works have reported that daily levels of $\mathrm{NO}_{2}$ in Valencia are associated with cardiovascular admissions $[5,6] . \mathrm{NO}_{2}$ is also a precursor of other secondary pollutants that are related to photochemical smog and acid rain. There are no previous studies on the temporal variability of $\mathrm{NO}_{2}$ and its relation with meteorological and emission changes in the Valencia urban area.

\section{Material and methods}

\subsection{Study area and data}

Valencia has around 1 million inhabitants. It is a typical Mediterranean city in terms of its urban structure and climatology. For monitoring and control purposes an automatic air pollution network is operated in the whole urban area by the local government. The network design and monitoring criteria follow the Air Quality Framework Directive and subsequent Daughter Directives (1996/62/EC, 1999/30/EC and 2000/60/EC). The network is subject to quality assurance and quality control procedures, which ensure the reliability of data. Hourly nitrogen oxides measurements are provided by the network. Mass concentrations of nitrogen oxides are determined using chemiluminescence method. Concentrations are expressed in $\mu \mathrm{g} / \mathrm{m}^{3}$. The volumes are standardized at a temperature of $293^{\circ} \mathrm{K}$ and a pressure of $101.3 \mathrm{kPa}$. Hourly meteorological observations are available in two background monitoring stations: P.Silla and Viveros. The P.Silla station site is a roadside site located a few meters from a motorway. The Viveros station site is located in a main street in downtown Valencia with high traffic density. The meteorological variables are: wind direction (WD, degrees), wind speed (WS, $\mathrm{m} / \mathrm{s}$ ), temperature $\left(\mathrm{T},{ }^{\circ} \mathrm{C}\right)$, relative humidity $(\mathrm{RH}, \%)$, pressure $(\mathrm{P}, \mathrm{mbar})$ and solar radiation $\left(\mathrm{SR}, \mathrm{W} / \mathrm{m}^{2}\right)$. At Viveros station RH and P are only observed at 0:00 am, 7:00 am, 1:00 pm and 6:00 pm and their records are not used in the analysis of this site. 
There are no traffic data available at P.Silla and Viveros. Nitric oxide (NO) concentrations can be used as an indicator of traffic emissions. NO is emitted primarily by motor vehicles, making it a strong indicator of vehicle emissions [1]. Ambient air $\mathrm{NO}_{2}$ is in large part originated by the oxidation of NO. The link between climate and pollutants plays an important role on the variability of $\mathrm{NO}$ and $\mathrm{NO}_{2}$, and has to be understood to select optimal pollutant reduction strategies and avoid exceeding emission directives.

The period analyzed in P.Silla is $1^{\text {st }}$ January $2001-31^{\text {st }}$ July 2006, and in Viveros $1^{\text {st }}$ January $2002-31^{\text {st }}$ July 2006 . The hourly means of $\mathrm{NO}_{2}$ have not exceeded at P.Silla and Viveros during the study period, neither the limit value nor the alert threshold set by the European Council Directive 1999/30//EC. However the limit value of this pollutant for the protection of human health in a calendar year has been exceeded in 2003, 2004 and 2005 in P.Silla. The highest annual $\mathrm{NO}_{2}$ mean was observed in 2003 in P.Silla.

The percentage of missing values, mean, standard deviation, maximum, percentiles of $\mathrm{NO}_{2}, \mathrm{NO}$ and meteorological data on an hourly basis are given in Table 1. Mean and percentile values of $\mathrm{NO}_{2}$ and $\mathrm{NO}$ are higher at the P.Silla site, while the lowest concentrations are recorded at Viveros station.

Table 1: Statistics for the hourly observations of meteorological and pollution variables at the two study stations.

\begin{tabular}{|c|c|c|c|c|c|c|c|c|}
\hline \multirow{4}{*}{ Site } & & $\%$ & & Std. & & \multicolumn{3}{|c|}{ Percentiles } \\
\hline P.Silla & Variable & miss & Mean & Dev. & Max. & 50 & 75 & 95 \\
& $\mathrm{NO}_{2}$ & 14 & 56.3 & 28.5 & 258 & 53 & 74 & 108 \\
& $\mathrm{NO}$ & 14 & 47.7 & 54.5 & 624 & 30 & 57 & 155 \\
& $\mathrm{WS}$ & 6.4 & 1.1 & 0.9 & 8.6 & 0.9 & 1.6 & 2.8 \\
& $\mathrm{WD}$ & 6.3 & 186.5 & 107.1 & 360 & 219 & 287 & 323 \\
& $\mathrm{~T}$ & 6.5 & 18.7 & 6.5 & 38.2 & 18.5 & 24 & 29.3 \\
& $\mathrm{RH}$ & 6.5 & 60.8 & 15.2 & 103 & 63 & 73 & 82 \\
& $\mathrm{P}$ & 6.3 & 1022.8 & 6.9 & 1046 & 1023 & 1027 & 1035 \\
& $\mathrm{SR}$ & 4.5 & 151.8 & 244.5 & 961 & 3 & 237 & 720 \\
\hline Viveros & $\mathrm{NO}$ & 23.4 & 36.1 & 24.5 & 238 & 31 & 52 & 82 \\
& $\mathrm{NO}$ & 23.4 & 19 & 37.3 & 596 & 5 & 18 & 86 \\
& $\mathrm{WS}$ & 25.5 & 1.8 & 1.3 & 11.9 & 1.4 & 2.5 & 4.4 \\
& $\mathrm{WD}$ & 25.5 & 183.8 & 108.7 & 360 & 220 & 270 & 350 \\
& $\mathrm{~T}$ & 10.4 & 18.9 & 6.4 & 38.2 & 18.8 & 24 & 29 \\
& $\mathrm{SR}$ & 5.8 & 180.3 & 265.3 & 1033 & 8 & 314 & 781 \\
\hline
\end{tabular}

\subsection{Method of analysis}

The Kolmogorov-Zurbenko filter $\left(\mathrm{KZ}_{\mathrm{m} . \mathrm{p}}\right)$ is a low-pass filter produced by $\mathrm{p}$ repeated iterations of a simple moving average of window width $\mathrm{m}$ [3]. This filter removes apportions of high frequencies from time series of meteorological or pollutant data. The period of the smallest frequency removed is $m x p^{1 / 2}$. The 
$\mathrm{KZ}_{\mathrm{m}=14, \mathrm{p}=3}$ filter was applied to the logarithm of hourly $\mathrm{NO}, \mathrm{NO}_{2}$ and to hourly meteorological data. The logarithm transformation was employed in order to normalize pollutants data and so stabilize the variance. The language $\mathrm{R}[7,8]$ was used to perform the analysis. The output of the $\mathrm{KZ}_{14,3}$ filter represents the contributions of periodicities higher than 24 hours, and includes seasonal meteorological effects plus long-term trends due to changes in emissions during the study period. Periodicities below 24 hours (daily cycle) can be obtained as the difference between the time series and the output of $\mathrm{KZ}_{14,3}$.

The meteorological effects can be removed from $\mathrm{KZ}_{14,3} \log \mathrm{NO}_{2}$ and $\mathrm{KZ}_{14,3}$ $\log$ NO using eqn. (1) [3, 9]:

$$
\mathrm{KZ}_{14,3} \mathrm{X}(\mathrm{t})=\mathrm{b}_{0}+\sum \mathrm{b}_{\mathrm{i}} \mathrm{KZ}_{14,3} \operatorname{MET}(\mathrm{t})+\mathrm{a}(\mathrm{t})
$$

$\mathrm{X}(\mathrm{t})$ is the $\log$ pollutant concentrations time series, $\mathrm{b}_{\mathrm{i}}$ are the parameters to be estimated, and $\mathrm{KZ}_{14,3} \mathrm{MET}(\mathrm{t})$ are the filtered meteorological observations. The residuals $\mathrm{a}(\mathrm{t})$ represent changes in pollutant concentrations attributable to sources other than the meteorological variables, such as emission or long-term climate change. $\mathrm{KZ}_{8598,3} \mathrm{a}(\mathrm{t})$ is the long-term component (periodicities above 1.7 years) in emissions that are unexplained by meteorological variables. $\mathrm{a}(\mathrm{t})-\mathrm{KZ}_{8598,3} \mathrm{a}(\mathrm{t})$ represents changes due to other meteorological variables not measured in Valencia, but that may affect the temporal variability of pollutants.

Following the methodology of previous works [3, 10], the logarithm of pollutant concentrations time series $\mathrm{X}(\mathrm{t})$ can be represented by eqn. (2):

$$
\mathrm{X}(\mathrm{t})=\mathrm{KZ}_{8598,3} \mathrm{a}(\mathrm{t})+\mathrm{SEASON} \mathrm{X}(\mathrm{t})+\mathrm{X}_{\mathrm{ST}}(\mathrm{t})
$$

SEASON $\mathrm{X}(\mathrm{t})$ is seasonal variation and $\mathrm{X}_{\mathrm{ST}}(\mathrm{t})$ is the short-term component. A natural logarithmic transformation is applied to the pollutant data and the model for the original observations is multiplicative:

$$
\text { Hourly pollutant concentration }(\mathrm{t})=\mathrm{e}^{\mathrm{KZ} a(t)} \mathrm{e}^{\mathrm{SEASON} \mathrm{X}(\mathrm{T})} \mathrm{e}^{\mathrm{Xst}(\mathrm{t})}
$$

The impact of meteorological variables and other well known effects involved in the temporal changes of $\mathrm{NO}_{2}$ or $\mathrm{NO}$, such as the night-day cycle, the so called weekend effect and pollutant transport from or to other places, belong to the seasonal and/or to the short-term fractions of the pollutants time series. The short-term component is attributable to weather and short-term fluctuations in emissions. Previous works (e.g. [11]) showed the need to study separately the long-term, seasonal and short-term components, because the physics of these temporal scales are different. An analysis of the relation between $\mathrm{KZ}_{8598,3} \mathrm{a}_{\mathrm{NO} 2}(\mathrm{t})$ and $\mathrm{KZ}_{8598,3} \mathrm{a}_{\mathrm{NO}}(\mathrm{t})$ may approximately estimate the traffic influence on the longterm component of the $\mathrm{NO}_{2}$ time series. $\mathrm{KZ}_{8598,3} \mathrm{a}_{\mathrm{NO}}(\mathrm{t})$ is used as a traffic indicator because it represents long-term changes in NO unexplained by seasonal and short-term effects. 


\section{Results and discussion}

\subsection{Temporal components}

$\mathrm{KZ}_{8598,3}$ and $\mathrm{KZ}_{14,3}$ filter were applied to obtain the long-term component, seasonal variation and short-term component of the logarithm of $\mathrm{NO}_{2}$ and $\mathrm{NO}$ series. Table 2 shows the relative contributions of these components to the time series total variance. The sum of percentages in Table 2 is not exactly $100 \%$ because the covariances were small and thus, ignored.

Table 2: $\quad$ Relative contribution (\%) of the temporal components.

\begin{tabular}{|c|c|c|c|c|c|c|c|c|}
\hline Component & $\begin{array}{c}\text { Log } \\
\mathrm{NO}_{2}\end{array}$ & $\begin{array}{c}\text { Log } \\
\text { NO }\end{array}$ & WS & WD & T & RH & P & SR \\
\hline $\begin{array}{c}\text { Long-term } \\
\text { P.Silla }\end{array}$ & 1.2 & 2.4 & 0.6 & 0.1 & 0.2 & 0.2 & 3.2 & 0.1 \\
Viveros & 0.2 & 0.7 & 0.3 & 0.5 & 0.9 & & & 0.1 \\
\hline Seasonal & & & & & & & & \\
P.Silla & 48.2 & 42.7 & 43.1 & 31.8 & 85.1 & 58.9 & 89 & 10.7 \\
Viveros & 50.1 & 43.6 & 40.5 & 27.4 & 80.2 & & & 14.3 \\
\hline Short-term & & & & & & & & \\
P.Silla & 45 & 46.9 & 44.3 & 58.1 & 12.5 & 19.9 & 2.2 & 76.9 \\
Viveros & 43.2 & 47.9 & 48.6 & 64.2 & 14.5 & & & 73.5 \\
\hline
\end{tabular}

The first two rows of Table 2 show the fraction of total variability explained by the long-term component (periodicities above 1.7 years). Seasonality has been analyzed as periodicities between 24 hours and 1.7 years (differences between days of the week, including the weekend effect, and between months). This component represents more than $40 \%$ of the total temporal variability in the study period. The variability attributable to the daily cycle (short-term component) is also more than $40 \%$ for the pollutants and the meteorological variables WS, WD and SR. The $\log \mathrm{NO}_{2}$ daily cycle has a $45 \%$ contribution in P.Silla and $43.2 \%$ contribution in Viveros.

\subsection{Estimation of meteorological effects}

Table 3 shows the results of the estimation of eqn. (1) at the two monitoring stations P.Silla and Viveros. The dependent variables were $\mathrm{KZ}_{14,3} \mathrm{NO}_{2}$ and $\mathrm{KZ}_{14,3} \mathrm{NO}$. Forward stepwise regression was use to select the $\mathrm{KZ}_{14,3}$ filtered meteorological variables. The last column in Table $3\left(\Delta \mathrm{R}^{2}\right)$ gives the increase in the variance explained when a variable is introduced into the equation. $\Delta \mathrm{R}^{2}$ is used to detect the candidate meteorological variables than explain more variability.

Filtered wind speed $\left(\mathrm{KZ}_{14,3} \mathrm{WS}\right)$ turned out to be the most important variable for the two pollutants in P.Silla. Pollutant transport explains $15.5 \%$ of changes in $\log \mathrm{NO}_{2}$ between days, months and years in this station. For log NO this factor explains $16.1 \%$ of its temporal variability for periodicities above 24 hours. The 
Table 3: $\quad$ Models suggested through the stepwise regression process.

\begin{tabular}{|c|c|c|c|}
\hline $\begin{array}{c}\text { Station and } \\
\text { pollutant }\end{array}$ & $\begin{array}{l}\text { Meteorological } \\
\text { variable }\end{array}$ & $\begin{array}{c}\text { Fitted } \\
\text { Parameter }\left(b_{i}\right)\end{array}$ & $\Delta \mathrm{R}^{2}$ \\
\hline $\begin{array}{c}\text { P.Silla } \\
\mathrm{KZ}_{14,3} \log \mathrm{NO}_{2} \\
\text { Variance } \\
\text { explained }=26.6 \% \\
\text { Residual standard } \\
\text { deviation }=0.36\end{array}$ & $\begin{array}{c}\mathrm{KZ}_{14,3} \mathrm{WS} \\
\mathrm{KZ}_{14,3} \mathrm{~T} \\
\mathrm{KZ}_{14,3} \mathrm{RH} \\
\mathrm{KZ}_{14,3} \mathrm{P} \\
\mathrm{KZ}_{14,3} \mathrm{WD}\end{array}$ & $\begin{array}{c}-0.311 \\
-0.014 \\
-0.003 \\
0.009 \\
0.001 \\
\end{array}$ & $\begin{array}{l}15.5 \\
6.5 \\
2.4 \\
1.4 \\
0.8 \\
\end{array}$ \\
\hline $\begin{array}{c}\text { Viveros } \\
\mathrm{KZ}_{14,3} \log \mathrm{NO}_{2} \\
\text { Variance } \\
\text { explained }=31.4 \% \\
\text { Residual standard } \\
\text { deviation }=0.47\end{array}$ & $\begin{array}{c}\mathrm{KZ}_{14,3} \mathrm{~T} \\
\mathrm{KZ}_{14,3} \mathrm{WD} \\
\mathrm{KZ}_{14,3} \mathrm{WS} \\
\mathrm{KZ}_{14,3} \mathrm{SR}\end{array}$ & $\begin{array}{c}-0.032 \\
0.004 \\
-0.241 \\
-4.6 \mathrm{e}-04\end{array}$ & $\begin{array}{c}17.7 \\
4 \\
9.3 \\
0.4\end{array}$ \\
\hline $\begin{array}{c}\text { P.Silla } \\
\mathrm{KZ}_{14,3} \log \mathrm{NO} \\
\text { Variance } \\
\text { explained }=40.2 \% \\
\text { Residual standard } \\
\text { deviation }=0.51\end{array}$ & $\begin{array}{c}\mathrm{KZ}_{14,3} \mathrm{WS} \\
\mathrm{KZ}_{14,3} \mathrm{~T} \\
\mathrm{KZ}_{14,3} \mathrm{WD} \\
\mathrm{KZ}_{14,3} \mathrm{P} \\
\mathrm{KZ}_{14,3} \mathrm{RH} \\
\mathrm{KZ}_{14,3} \mathrm{SR} \\
\end{array}$ & $\begin{array}{c}-0.435 \\
-0.035 \\
0.004 \\
0.009 \\
0.004 \\
2.6 \mathrm{e}-04 \\
\end{array}$ & $\begin{array}{c}16.1 \\
15 \\
8.1 \\
0.7 \\
0.2 \\
0.09 \\
\end{array}$ \\
\hline $\begin{array}{c}\text { Viveros } \\
\mathrm{KZ}_{14,3} \log \mathrm{NO} \\
\text { Variance } \\
\text { explained }=29.3 \% \\
\text { Residual standard } \\
\text { deviation }=0.69\end{array}$ & $\begin{array}{c}\mathrm{KZ}_{14,3} \mathrm{~T} \\
\mathrm{KZ}_{14,3} \mathrm{WD} \\
\mathrm{KZ}_{14,3} \mathrm{WS} \\
\mathrm{KZ}_{14,3} \mathrm{SR}\end{array}$ & $\begin{array}{c}-0.036 \\
0.005 \\
-0.345 \\
-0.001\end{array}$ & $\begin{array}{c}15.1 \\
4.2 \\
9 \\
1\end{array}$ \\
\hline
\end{tabular}

second most important variable was $\mathrm{KZ}_{14,3} \mathrm{~T}$, explaining $6.5 \%$ of the variability of $\log \mathrm{NO}_{2}$ and $15 \%$ of the variability of $\log \mathrm{NO}$.

At the Viveros monitoring site filtered temperature was the most relevant explanatory variable and the second one was filtered wind speed. These results are a consequence of the annual cycle of the pollutants concentrations. The highest pollution levels are recorded in months with low temperatures. NO emissions increase in these months. Pollutants levels are higher with reduced traffic speed, which in Valencia occurs during winter months when the study locations have a greater traffic density. When temperatures are higher oxides of nitrogen are important precursors of other pollutants such as ozone. It is well known that ozone is produced owing to the interaction of meteorology and nitrogen oxides as well as other factors [12].

Table 3 also gives the total variance explained by the model with the filtered meteorological variables. These values are lower than those observed in previous 
works on ozone $[3,9,10]$. Nitrogen oxides variability is less dependent on meteorological changes than ozone. The percentages of variance that appear in Table 3, indicate that there are other factors, such as traffic, that also have an effect on $\mathrm{NO}_{2}$ and $\mathrm{NO}$ periodicities above 24 hours.

\subsection{Long-term changes in $\mathrm{NO}_{2}$ emissions}

Meteorologically adjusted NO is used as an indicator of traffic density because there is no traffic data available at the two sampling stations. The relationship between the long-term variation of $\mathrm{NO}_{2}$ emissions, $\mathrm{KZ}_{8598,3} \mathrm{a}_{\mathrm{NO} 2}(\mathrm{t})$, and the longterm evolution of the traffic indicator, $\mathrm{KZ}_{8598,3} \mathrm{a}_{\mathrm{NO}}(\mathrm{t})$, indicates that traffic emissions play an important role in the long-term trend of $\mathrm{NO}_{2}$ concentrations.

From a joint analysis of $\mathrm{KZ}_{8598,3} \mathrm{a}_{\mathrm{NO} 2}(\mathrm{t})$ and $\mathrm{KZ}_{8598,3} \mathrm{a}_{\mathrm{NO}}(\mathrm{t})$ at the two study locations, a second-order relationship could be seen among the long-term components of $\mathrm{NO}_{2}$ and NO. Table 4 shows the parameters and the results of the models estimation.

Table 4: Parameters and variance explained of the second-order model of the relationship between the long-term fraction of $\mathrm{NO}_{2}$ and the long-term fraction of NO.

\begin{tabular}{|c|c|c|c|}
\hline \multicolumn{4}{|c|}{ Model parameters } \\
\hline $\begin{array}{c}\text { P.Silla } \\
\text { Variance } \\
\text { explained=36.1\% }\end{array}$ & Constant & Linear term & Quadratic term \\
\hline $\begin{array}{c}\text { Viveros } \\
\text { Variance } \\
\text { explained=81.3\% }\end{array}$ & -0.044 & 0.704 & 1.792 \\
\hline
\end{tabular}

The parameters are different at the two sampling sites due to the spatial variability of the $\mathrm{NO}_{2}$ field. The long-term fraction of $\mathrm{NO}_{2}$ shows a stronger relationship with the long-term fraction of $\mathrm{NO}$ at the Viveros station than at the P.Silla station. In Viveros station the second-order model explains $81.3 \%$ of the variability of the meteorologically-adjusted (filtered) $\mathrm{NO}_{2}$ time series. $\mathrm{NO}_{2}$ longterm changes at this station are mainly explained by traffic. In P.Silla station the percentage of variance explained is only $36.1 \%$.

\section{Conclusions}

Temporal changes in hourly $\mathrm{NO}_{2}$ concentrations have been analyzed at two locations within Valencia urban area (Spain). The study period was January 2001-July 2006 at one site (P.Silla station) and January 2002-July 2006 at the other (Viveros station). Previous epidemiological studies have shown a significant connection between health problems and an increase in $\mathrm{NO}_{2}$ pollution in the study area. Furthermore, the $\mathrm{NO}_{2}$ limit value for the protection of human health in a calendar year was exceed in several years at one of the study locations. $\mathrm{NO}_{2}$ is a problematic pollutant in Valencia. 
The analysis of temporal variations of pollutants is useful when evaluating the effectiveness of plans and regulations to reduce emissions. The assessment of long-term changes to evaluate reduction strategies has to be done while taking into account meteorological variability. In this study, the Kolmogorov-Zurbenko (KZ) filter has been used to separate both meteorological and air quality data into short-term, seasonal and long-term trend components. Long-term components represent a small amount in the overall variability of air pollution data. Seasonal and short-term components mask the underlying relationship between $\mathrm{NO}_{2}$ and emissions if studied as a whole. Therefore, the temporal components of the air pollutants have to be studied separately due to their different physics and explanatory mechanisms. An estimate of the sum of the seasonal and long-term components (periodicities above 24 hours) is provided by the KZ filter (widow size $=14$, iterations $=3$ ). The pollutants series have been transformed using the natural logarithm function sue to lack of normality.

The effect of meteorology in the natural logarithm of $\mathrm{NO}_{2}$ time series has been filtered out by analyzing the relationship between their temporal components. Forward stepwise regression was applied to select the filtered meteorological variables that explained more variability. Taking into account that a natural logarithmic transformation has been applied to the pollutants time series of hourly data, the model for the original concentrations is multiplicative. The variability of $\mathrm{NO}_{2}$ changes above 24 hours explained by the candidate meteorological variables is $26.6 \%$ at the P.Silla station and $31.4 \%$ at the Viveros station.

As there is no traffic data available at the two sampling sites, meteorologically-adjusted NO is used as an indicator of traffic density. The longterm changes (periodicities above 1.7 years) in $\mathrm{NO}_{2}$ emissions unexplained by meteorological variables, are estimated with the application of the $\mathrm{KZ}$ filter (window size $=8598$, iterations $=3$ ) to the residuals of the stepwise regression analysis. The long-term variation of $\mathrm{NO}_{2}$ emissions shows a non-linear relationship with the long-term evolution of the traffic indicator NO. The dependencies of urban $\mathrm{NO}_{2}$ on the corresponding vehicular emissions are nonlinear. At the Viveros location the meteorologically-adjusted NO observations explain $81.3 \%$ of the variability of $\mathrm{NO}_{2}$ long-term changes, while at the P.Silla station this percentage is only $36.1 \%$, Therefore traffic is a major factor in $\mathrm{NO}_{2}$ formation at the Viveros site. At P.Silla changes in emissions are more related to other factors. The seasonal component of $\mathrm{NO}_{2}$ time series is only dependent on meteorology and therefore no measure can be adopted to reduce its effects. The short-term component is very close to being white noise (independent observations).

The analysis method could be extended to study other pollutants variability within Valencia urban area. The approach could also be applied in other areas with similar air quality problems and meteorological and traffic influences. The study involves the following inherent limitations. Concentrations have been analyzed at two specific spatial locations within Valencia. This city is situated on a fairly flat terrain; clearly, the study of pollutants variability and their prediction is more complex in cities located in hilly or mountainous terrain. The 
performance of the analysis using traffic data as an explanatory variable may improve the explanatory power of the approach. Ibarra-Berastegi et al. [9] have shown that long-term changes of the mean traffic flow are responsible for longterm changes in ozone within Bilbao (Spain). Further work is also required regarding the results obtained in the present study, including an investigation of and comparison with alternative models. The application of neural networkbased models is a promising research area to analyze the relationship between nitrogen oxides and meteorology.

\section{References}

[1] World Health Organization, Health Aspects of Air Pollution with Particulate Matter, Ozone and Nitrogen Dioxide, report on a WHO Working Group, Bonn, Germany, 2003.

[2] Chauhan, A.J. \& Johnston, S.L., Air pollution and infection in respiratory illness, British Medical Bulletin, 68, pp. 95-112, 2003.

[3] Rao, S.T. \& Zurbenko, I.G., Detecting and tracking changes in ozone air quality, Journal of the Air and Waste Management Association, 44, pp. 1089-1092, 1994.

[4] Tenias, J.M, Ballester, F. \& Rivera, M.L., Association between hospital medical emergency visits for asthma and air pollution in Valencia, Spain, Journal of Occupational and Environmental Medicine, 55, pp. 541-547, 1998.

[5] Ballester, F., Tenias, J.M. \& Pérez-Hoyos, S., Air pollution and emergency hospital admissions for cardiovascular diseases in Valencia, Spain, Journal of Epidemiology and Community Health, 55, pp. 57-65, 2001.

[6] Ballester, F., Rodríguez, P., Iñíguez, C., Sáez, M., Daponte, A. et al., Air pollution and cardiovascular admissions association in Spain: result within the EMECAS project, Journal of Epidemiology and Community Health, 60, pp. 328-336, 2006.

[7] R Development Core Team, $R$, A Language and Environment for Statistical Computing, R Foundation for Statistical Computing, Vienna, Austria, ISBM 3-900051-07-0, URL http://www.R-project.org, 2011.

[8] Close, B. \& Zurbenko, I.G., kza: Kolmogorov-Zurbenko adaptative filter for image detection, $\mathrm{R}$ package: version 0.91, 2005.

[9] Ibarra-Berastegi, G., Madariaga, I., Elías, A., Agirre, E. \& Uría, J., Longterm changes of ozone and traffic in Bilbao, Atmospheric Environment, 35, pp. 5581-5592, 2001.

[10] Wise, E.S. \& Comrie, A.C., Extending the Kolmogorov-Zurbenko filter: Application to ozone, particulate matter and meteorological trends, Journal of the Air and Waste Management Association, 55, pp. 1208-1216, 2005.

[11] Zurbenko, I. \& Sowizral, M., Resolution of the destructive effect of noise on linear regression of two time series, Far East Journal of Theoretical Statistics, 3, pp. 139-157, 1999.

[12] Brimblecombe, P., Air Composition and Chemistry, 2nd Ed, Cambridge University Press, 267 pp., 1995. 